\title{
THE EFFECT OF PIRACETAM ON VALPROIC ACID INDUCED CONGENITAL MALFORMATIONS IN SWISS ALBINO MICE.
}

\author{
Shrestha $\boldsymbol{S}^{1}$, Singh $\mathbf{M}^{1}$, Mishra $\mathbf{S P}^{2}$
}

${ }^{1}$ Department of Anatomy, ${ }^{2}$ Deparment of Biochemistry, Institute of Medical Sciences, Banaras Hindu University, Varanasi, UP, India.

\begin{abstract}
Valproic acid (VPA) is an antiepileptic drug which is widely used in humans and is a well known teratogenic agent when used during pregnancy. Piracetam is a nootropic or cognitive enhancer drug used to treat cognitive impairment in aging, brain injuries as well as dementia. In the present study, these two drugs VPA and Piracetam were administered orally to Swiss albino mice in the doses of $400 \mathrm{mg} / \mathrm{kg}$ and $800 \mathrm{mg} / \mathrm{kg}$ body weight respectively from gestational day (GD) 6-11 in order to see the protective effect of Piracetam against VPA induced teratogenesis. The fetuses were collected on GD 18 after uterotomy and observed for gross malformations if any. In VPA treated group the malformations observed were exencephaly, cranioschisis, limb and tail defects, haemorrhage, resorptions and retardation. No such anomalies were observed in control and Piracetam treated groups. However, in VPA+Piracetam treated group some resorptions and growth retardation were noted. This group showed highly significant $(p<0.001)$ protection against the teratogenic effects of VPA treated group though the developmental parameters were significantly reduced $(p<0.001)$ in comparison to those of group I (control) and group III (receiving piracetam). These findings suggest that Piracetam, if given in higher doses might protect the development in utero against the teratogenic effects of VPA.
\end{abstract}

\section{KEYWORDS}

Valproic acid, Piracetam, mice, exencephaly, cranioschisis, tail defects

\section{CORRESPONDING AUTHOR}

Dr. Shamsher Shrestha,

Department of Anatomy,

B.P. Koirala Institute of Health Sciences,

Dharan, Nepal.

Email: shamsher2002@gmail.com

ORCID ID: 0000-0002-0547-7823 


\section{INTRODUCTION}

Valproic acid (VPA) is a broad spectrum anticonvulsant and is widely used in the treatment of various types of seizure disorders and some psychiatric problems. This is believed to affect the function of the neurotransmitter GABA in the human brain. Its mechanism of action includes enhanced neurotransmission of GABA (by inhibiting GABA transaminase). It also blocks the voltage-gated sodium channels and T-type calcium channels. These mechanisms make it a broad spectrum anticonvulsant drug. However, several other mechanisms of action in neuropsychiatric disorders have been proposed for VPA. ${ }^{1}$

VPA is a well established human teratogen. ${ }^{2}$ Its exposure during pregnancy may result in an increased incidence of neural tube defects and a number of other major and minor malformations. ${ }^{3-6}$ Review of literature reveals that effective teratogenicity of VPA is dose dependent and it is a potent inducer of malformations of multiple organs in rat, mice, rabbit, zebrafish, monkey etc. ${ }^{7-11}$ In humans, intrauterine exposure to VPA has been associated with mental retardation, cognitive impairment, behavioral deficits and neurodevelopmental delay. ${ }^{12-15}$

Piracetam (2-oxo-1-pyrollidine acetamide) is a cyclic derivative of gamma-aminobutyric acid (GABA) but it does not exhibit any GABA-like activity in animals. It is completely absorbed after oral administration. It is one of nootropic drugs, used in many countries to treat cognitive impairment in aging, brain injuries as well as dementia. ${ }^{16,17}$ These are claimed to improve the higher telencephalic integrative activities in the brain and restore deficient higher nervous system activity without affecting subcortical functions. ${ }^{18}$ Unlike other psychotropic drugs, nootropics do not cause sedation or stimulation and are completely devoid of toxic effects, even when administered in very high doses. Piracetam has been reported to possess cytoprotective, antioxidant, antihypoxic and microcirculation protective effects. ${ }^{19-22}$
It is believed that Piracetam being labeled as a nootropic or smart drug could possibly play a significant role against teratogenicity. Therefore, the aim of the present study is to investigate whether Piracetam (with its proven cyto-protective and antioxidant properties) can reduce the intensity of teratogenicity induced in pregnant Swiss albino mice by VPA which is a known potent teratogen.

\section{MATERIALS AND METHODS}

Adult female Swiss albino mice (25-30 gm) were used in the present study after approval by animal ethics committee of Banaras Hindu University Varanasi, India. All experimental animals were housed under Standard laboratory conditions $\left(25^{\circ} \pm 2^{\circ} \mathrm{C}, 12 \mathrm{hr}\right.$ L/D cycle, $\left.60 \% \mathrm{RH}\right)$ with free access to food and water in the animal house of the Department of Anatomy, Institute of Medical Sciences, Banaras Hindu University, Varanasi. The mice were kept for mating in the evening and the presence of vaginal plug on the following morning was designated as day 0 of gestation. The pregnant mice were divided into four groups, each group contained eight mice. Group I served as control, group II received VPA $400 \mathrm{mg} / \mathrm{kg} /$ day from GD6-GD11, group III received Piracetam $800 \mathrm{mg} / \mathrm{kg} /$ day from GD6-GD11 and group IV received VPA + Piracetam at the same dose and day mentioned earlier. All these drugs were given by oral route. All the groups of pregnant mice were sacrificed on day 18 of gestation by deep ether anaesthesia and fetuses and placenta were collected. The fetuses were blotted dry, weighed individually and grossly examined for any external malformations. The crown rump length (CR length) was measured with the help of a Vernier caliper.

\section{RESULTS}

The average weight of fetuses was $1.180 \pm 0.153$ gm in Group I (Control) and $0.796 \pm 0.138 \mathrm{gm}$ in Group II (VPA treated fetuses). In Group III

Table 1: Mean weight and CR length in control and treated fetuses collected on day 18 of pregnancy

\begin{tabular}{|lccc|} 
Groups & No. of fetuses & $\begin{array}{c}* \text { Mean } \pm \text { SD of wt. } \\
\text { (in grams) }\end{array}$ & $\begin{array}{c}* * \text { Mean } \pm \text { SD of CR } \\
\text { length (in mm) }\end{array}$ \\
Control & 36 & $1.180 \pm 0.153$ & $24.13 \pm 1.407$ \\
Valproic acid & 42 & $0.796 \pm 0.138$ & $19.88 \pm 2.154$ \\
Piracetam & 30 & $1.107 \pm 0.151$ & $24.13 \pm 1.814$ \\
Valproic acid + Piracetam & 41 & $0.976 \pm 0.136$ & $22.12 \pm 1.691$ \\
\hline
\end{tabular}

${ }^{*}$ F value $=55.39, \mathrm{df}=(3,152), \mathrm{p}<0.001 ;{ }^{* *} \mathrm{~F}$ value $=51.29, \mathrm{df}=(3,152), \mathrm{p}<0.001$ 


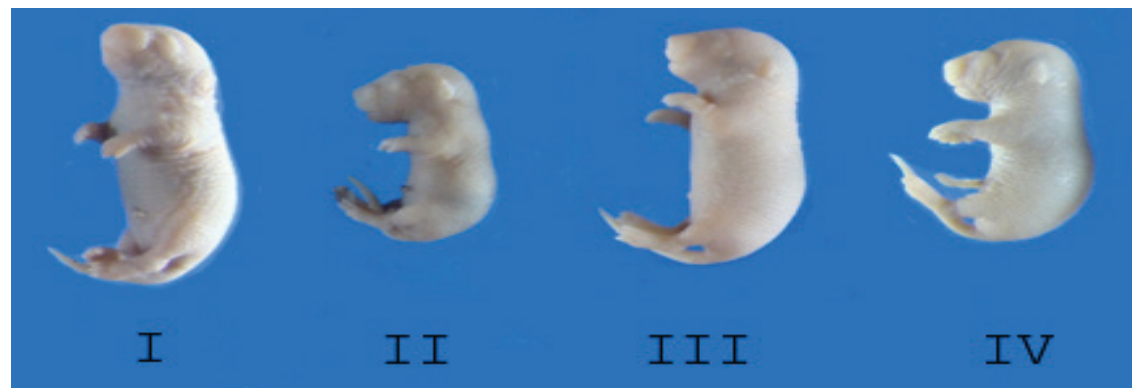

Fig. 1: Photograph showing fetuses from different groups: I- Control, II - VPA treated, III- Piracetam treated, IV- VPA + Piracetam treated

\section{Table 2: Inter Group Comparison (Post hoc test)}

\begin{tabular}{|lll|} 
Group & Weight & CR length \\
Control vs VPA & $\mathrm{p}<0.001$ & $\mathrm{p}<0.001$ \\
$\begin{array}{l}\text { Control vs Piracetam } \\
\text { (PCT) }\end{array}$ & $\mathrm{p}<0.05$ & $\mathrm{p}>0.05$ \\
Control vs VPA + PCT & $\mathrm{p}<0.001$ & $\mathrm{p}<0.001$ \\
VPA vs PCT & $\mathrm{p}<0.001$ & $\mathrm{p}<0.001$ \\
PCT vs VPA + PCT & $\mathrm{p}<0.001$ & $\mathrm{p}<0.001$ \\
VPA vs VPA + PCT & $\mathrm{p}<0.001$ & $\mathrm{p}<0.001$ \\
\hline
\end{tabular}

(Piracetam treated fetuses) the average weight was $1.107 \pm 0.151 \mathrm{gm}$ and in Group IV $(\mathrm{VPA}+$ Piracetam treated fetuses) it was $0.976 \pm 0.136 \mathrm{gm}$.

On comparison of the weight of fetuses of different groups, the reduction in weight of Group II (VPA treated fetuses) was highly significant in comparison to Group I as well as Group III ( $\mathrm{p}<$ 0.001). The reduction in the weight of the fetuses of Group IV was highly significant $(p<0.001)$ in comparison to Group I as well as Group III, but in comparison to Group II, the weight was significantly increased ( $p<0.001$ ), (Table-1 \& Table-2)

\section{Table 3: Resorption in control and treated fetuses collected on day 18 of Pregnancy}

\begin{tabular}{lccccc|} 
Groups & $\begin{array}{c}\text { No. of } \\
\text { animals }\end{array}$ & $\begin{array}{c}\text { No. of } \\
\text { implantation }\end{array}$ & $\begin{array}{c}\text { No. of dead/ } \\
\text { Under developed fetuses }\end{array}$ & $\begin{array}{c}\text { No. of } \\
\text { fetuses }\end{array}$ & $\begin{array}{c}\text { No. \& \% of } \\
\text { Resorption }\end{array}$ \\
Control & 8 & 63 & 2 & 59 & $2(3.17)$ \\
Valproic acid & 8 & 65 & 3 & 40 & $22(33.84)$ \\
Piracetam & 8 & 60 & 1 & 59 & $0(0.00)$ \\
Valproic acid + & 8 & 62 & 0 & 53 & $9(14.51)$ \\
Piracetam & 8 & & & &
\end{tabular}

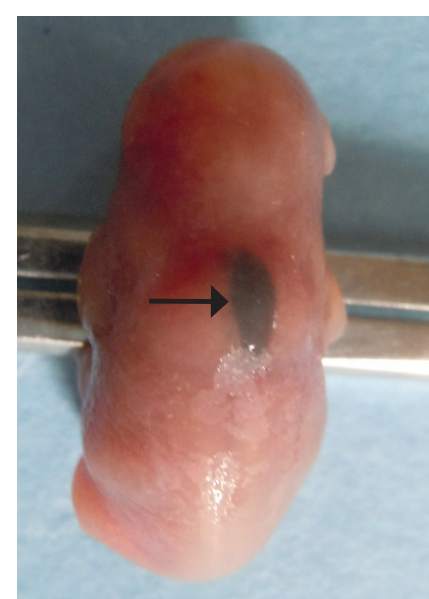

Fig. $2 \mathrm{~A}$

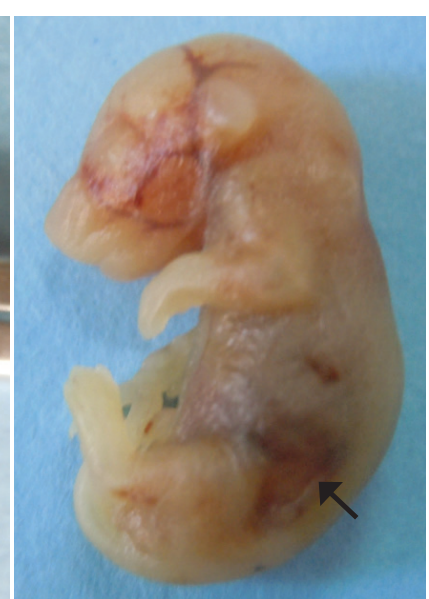

Fig. 2 B

Fig. 2 A \& 2 B: showing widespread subcutaneous haemorrhage (arrow) in group II

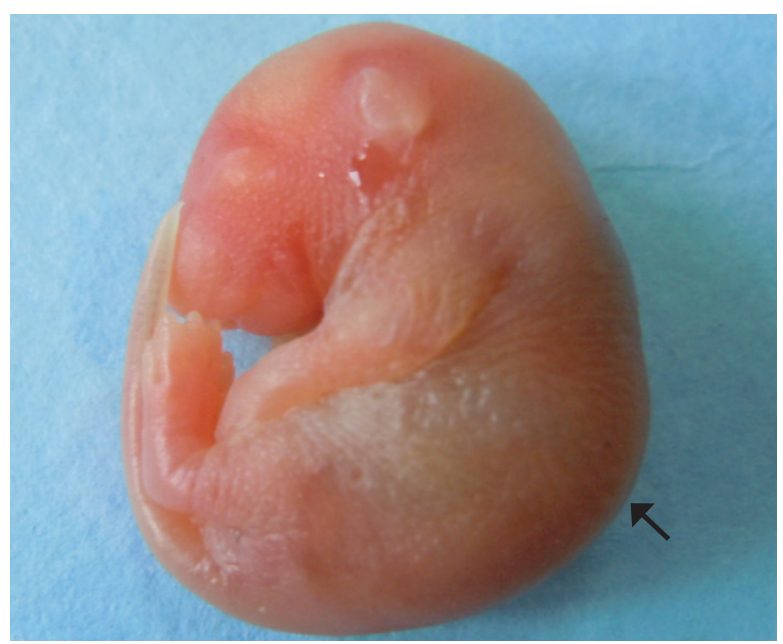

Fig. 3: Showing increased vertebral flexion (arrow) in group II 


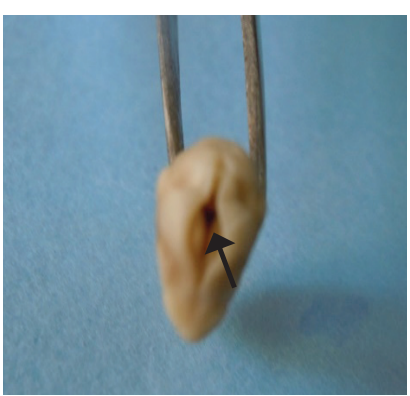

Fig. $4 \mathrm{~A}$

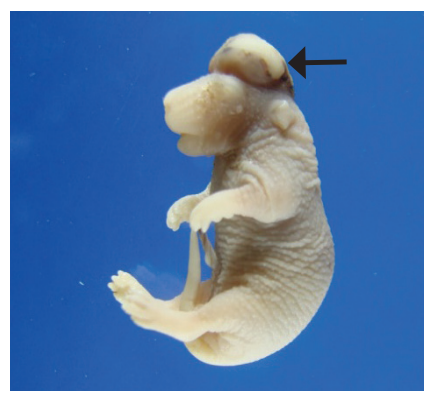

Fig. 4 B
Fig 4 A: Showing Cranioschisis (arrow) and 4 B: Showing Exencephaly (arrow) in group II

The average CR length of fetuses was $24.13 \pm 1.407$ $\mathrm{mm}$ in Group I (Control) and $19.88 \pm 2.154 \mathrm{~mm}$ in Group II (VPA treated fetuses). In Piracetam treated fetuses the length was $24.13 \pm 1.814 \mathrm{~mm}$ and in VPA+ Piracetam fetuses it was $22.12 \pm 1.691$ $\mathrm{mm}$.

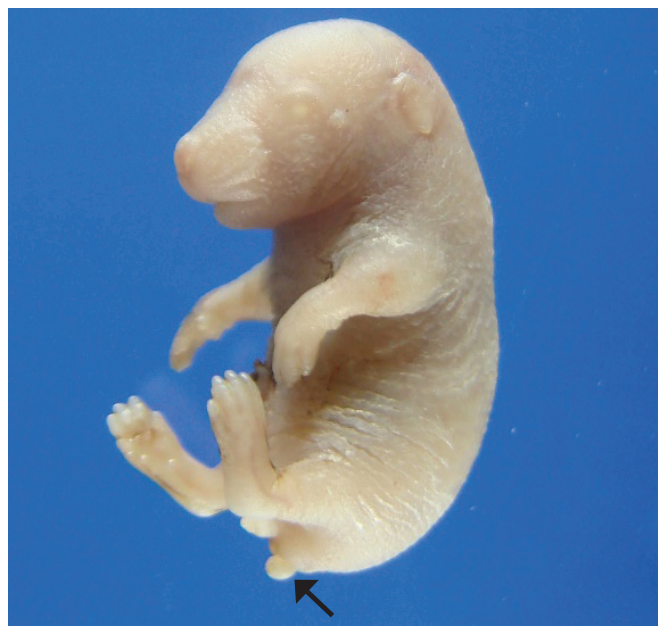

Fig 5: Showing rudimentary tail (arrow)

In accordance with the reduction in weight, the CR length of the fetuses was also reduced. In comparison to the Group I (Control fetuses) the reduction in length in Group II and IV was highly significant $(\mathrm{p}<0.001)$ but in Group III it was not significant $(p>0.05)$. The reduction in length of Group II and IV was highly significant $(\mathrm{p}<0.001)$ in comparison to that of Group III $(p<0.001)$. The significance of reduction was maximum in Group II followed by Group IV in comparison to Group I and III.

The resorption in Group II and Group IV treated mice was observed to be $33.84 \%$ and $14.51 \%$ respectively while $3.17 \%$ resorption was observed in Group I. No resorption was observed in Group III mice (Table 3).

In control group as well as Piracetam treated group no malformations of fetuses was observed. In VPA treated group highly significant decrease

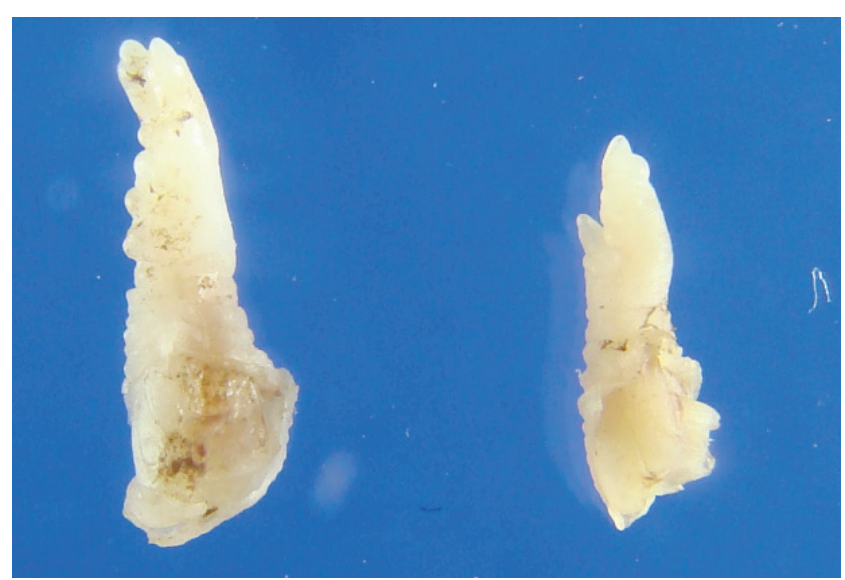

Fig 6: Showing syndactyly of $3^{\text {rd }}$ and $4^{\text {th }}$ digits

in the weight and length of fetuses was observed (Table 1 \& 2 and Fig. 1). In addition, marked subcutaneous haemorrhage was seen in most of the fetuses (Fig. 2A, 2B). Hyperflexion of the vertebral column was a common feature (Fig. 3). The fetuses exhibited cranioschisis as well as exencephaly (Fig. 4A, 4B). The tail defects included short tail, rudimentary and complete absence of tail (Fig. 5). The limb defects included adactyly, ectrodactyly, brachydactyly as well as globular paw with syndactyly of $3^{\text {rd }} \& 4^{\text {th }}$ digits (Fig. 6).

\section{DISCUSSION}

VPA is a widely used antiepileptic drug. It is known to reduce fetal weight drastically and is an established teratogen. ${ }^{2}$ This is known to cross the placenta and cause a wide spectrum of congenital anomalies. ${ }^{3-9}$

In the present study, incidence of resorption observed in VPA treated (Group II) and VPA + Piracetam treated (Group IV) mice was found to be $33.84 \%$ and $14.51 \%$ respectively while $3.17 \%$ resorption was seen in controls (Group I). No resorption was seen in Piracetam treated mice (Group III). Incidence of resorption in VPA + Piracetam treated mice was significantly low in comparison to VPA treated mice. The absence of resorption in Group III may be a chance factor.

The average weight and CR length of Group I, Group III and Group IV fetuses was significantly higher in comparison to Group II treated fetuses $(\mathrm{P}<0.001)$. The teratogenic mechanism of VPA seems to be multifaceted as it is reported to affect the cytoskeleton, cell motility, zinc, methionine, homocysteine and glutathione metabolism. ${ }^{23-27}$ It also affects the peroxisome proliferationactivated interaction and gene expression. ${ }^{28,29} \mathrm{It}$ has been shown to reduce vitamin $\mathrm{E} \mathrm{level}^{30}$ as well as folic acid. The deficiency of which is proved to be responsible for teratogenecity, especially 
neural tube defects as it acts as a coenzyme in reduction, DNA synthesis, protein metabolism and methyl donor reactions. ${ }^{31-33}$ Its lack can cause DNA hypomethylation and DNA fracture and thus abnormal gene productions. ${ }^{34}$ Under these effects, the intrauterine growth retardation and the related weight reduction appear to be associated with developmental toxicity effect of VPA. ${ }^{35-37}$ Haemorrhage, the blanket effect of VPA can be explained on the basis of its effect on methionine, homocysteine and glutathione metabolism. Increased vertebral (lumbar) flexion, limb defects and tail defects may be explained on the basis of its effect on cytoskeleton, cell motility and production of free oxygen radicals. The neural tube defects such as cranioschisis and exencephaly may be explained on the basis of loss of heterozygosity of gene critical development for which folic acid deficiency seems to be responsible. All these multifaceted effects of VPA pooled together may be responsible for VPA induced battery of congenital malformations. No particular effect can be assigned to any particular anomaly.

In the group treated with Piracetam the length of the fetuses was approximately equal to those of the controls though there was slight difference in weight. Piracetam improves mitochondrial function where conversion of food energy to the energy of ATP occurs. ${ }^{38}$ This helps in the oxidation of toxic compounds by mitochondrial enzymes. Thus the increased amount of antioxidants neutralise the effects of free oxygen radicals produced by VPA decreasing the number of apoptotic and dead cells. ${ }^{39}$ Hence, Piracetam protects against the induced deleterious effects of VPA on a given subject.
Piracetam stimulates prostacyclin synthesis which has vasodilator as well as platelet aggregation inhibitory properties. ${ }^{40}$ Due to this effect there is decreased adhesion of red blood cells to endothelium. This facilitates movements of erythrocytes through the circulation providing sufficient oxygen to the cells whether developing or developed. Thus it also neutralizes the toxic effects of free oxygen radicals. ${ }^{41}$

In the present study, in the group where Piracetam has been administered along with VPA, the congenital malformations are significantly reduced $(p<0.001)$ in comparison to those of only VPA treated group. It could not completely eliminate the effect of VPA which is a potent teratogen. The reason may be that the dose of Piracetam was not sufficient enough to protect against VPA. So, for proper protective function there has to be a proper balance between the dose of teratogen "VPA" and the dose of protective agent "Piracetam". It may be possible that higher doses of Piracetam would have protected the treated subjects. This suggests that Piracetam if given in higher doses in pregnant epileptic patients might protect the conceptus against the deleterious effects of VPA or may be other antiepileptic drugs also.

\section{ACKNOWLEDGEMENTS}

The authors would like to thank Dr. T. B. Singh, Professor of Biostatistics division of I.M.S., B.H.U., for his guidance and help in statistical analysis in this study.

\section{REFERENCES}

1. Rosenberg G. The mechanisms of action of valproate in neuropsychiatric disorders: can we see the forest for the trees? Cell Mol Life Sci 2007; 64: 2090-2103.

2. Asher Ornoy. Valproic acid in pregnancy: how much are we endangering the embryo and fetus? Reproductive Toxicol 2009; 28: 1-10.

3. Nau H. Valproic acid-induced neural tube defects. Ciba Found Symp 1994; 181: 144-52.

4. Wyszyski DF, Nambisan M, Surve T, Alsdorf RM, Smith CR, Holmes LB. Increased rate of major malformations in offsprings exposed to valproate during pregnancy. Neurology 2005; 64: 961-5.

5. Morrow J, Russell A, Guthrie E et al. Malformation risks of antiepileptic drugs in pregnancy: a prospective study from the UK Epilepsy and Pregnancy Register. J Neurol Neurosurg Psych 2006; 77: 193-8.

6. Jager-Roman E, Deichl A, Jakob S et al. Fetal growth, major malformations, and minor anomalies in infants born to women receiving valproic acid. $J$ pediatr 1986; 108: 997-1004.

7. Khera KS. Valproic acid- induced placental and teratogenic effects in rats. Teratology 1992; 45: 60310.

8. Sonoda T, Ohdo S, Ohba K, Okishima T, Hayakawa K. Teratogenic effects of sodium valproate in the JcI: ICR mouse fetus. Acta Paediatr Jpn 1990; 32: 502-7.

9. Paulson RB, Sucheston ME, Hayes TG, Paulson GW. Teratogenic effects of valproate in the CD-1 mouse fetus. Arch Neurol 1985; 42: 980-3.

10. Herrmann K. Effects of the anticonvulsant drug valproic acid and related substances on the early development of the Zebrafish (Brachydanio rerio). Toxicol In Vitro 1993; 7: 41-54 
11. Hendrickx AG, Nau H, Binkerd P et al. Valproic acid developmental toxicity and pharmacokinetics in the rhesus monkey: an interspecies comparison. Teratology 1988; 38: 329-45.

12. Vinten J, Adab N, Kini U, Gorry J, Gregg J, Baker GA. Neuropsychological effects of exposure to anticonvulsant medication in utero. Neurology 2005; 64: 949-954.

13. Kozma C. Valproic acid embryopathy: report of two siblings with further expansion of the phenotypic abnormalities and a review of the literature. Am J Med Genet 2001; 98: 168-75.

14. Moore SJ, Turnpenny P, Quinn A et al. A clinical study of 57 children with fetal anticonvulsant syndromes. J med Genet 2000; 37: 489-97.

15. Adab N, Kini U, Vinten J et al. The longer term outcome of children born to mothers with epilepsy. J Neurol Neurosurg psychiatry 2004; 75: 1575-83.

16. Croisile B, Trillet M, Fondarai J, Laurent B, Mauguiere F, Billardon M. Long term and high dose pirecetam treatment of Alzheimer's disease. Neurology 1993; 43: 301-5.

17. Waegemans T, Wilsher CR, Danniau A, Ferris SH, Kurz A, Winblad B. Clinical efficacy of pirecetam in cognitive impairment: a meta analysis. Demnet Geriatr Cogn Disord 2002; 13: 217-24 .

18. Giurgea C.E. The nootropic concept and its prospective implications. Drug Dev Res 1982; 2: 441-6.

19. Tortiglione A, Minale M, Pignataro G, Amoroso S, DiRenzo G, Annunziato L. The 2-oxopyrrolidinacetamide pirecetam reduces infarct brain volume induced by permanent middle cerebral artery occlusion in male rats. Neuropharmacology 2002; 43: 427-33.

20. Stockmans F, Deberdt W, Nystrom A et al. Inhibitory effect of pirecetam on platelet-rich thrombus formation in an animal model. Thromb Haemost 1998; 79: 222-7.

21. Horvath $\mathrm{B}$, Marton $\mathrm{Z}$, Halmosi $\mathrm{R}$ et al. In vitro antioxidant properties of pentoxifylline, pirecetam, and Vinpocetine. Clin Neuropharmacol 2002; 25: 37-42.

22. Xerri C, Zennou-Azougui Y, Coq JO. Neuroprotective effects on somatotopic maps resulting from pirecetam treatment and environmental enrichment after focal cortical injury. ILARJ 2003; 44: 110-24.

23. Walmod PS, Foley A, Berezin A et al. Cell motility is inhibited by the antiepileptic compound, valproic acid and its teratogenic analogues. Cell Motil Cytoskeleton 1998; 40: 220-37.

24. Walmod PS, Skladchikova G, Kawa A, Berezin V, Bock E. Antiepileptic teratogen valproic acid (VPA) modulates organization and dynamics of the actin cytoskeleton. Cell Motil Cytoskeleton 1999; 42: 24155.

25. Bui LM, Taubeneck MN, Commisso JF, Uriu-Hare JY, Faber WD, Keen CL. Altered Zinc metabolism contributes to the developmental toxicity of 2-ethylhexanoic acid, 2-ethylhexanol and valproic acid. Toxicology 1998; 126: 9-21.

26. Alonso-Aperte E, Ubeda N, Achon M, PerezMiquelsanz J, Varela- Moreiras G. Impaired methionine synthesis and hypermethylation in rats exposed to valproate during gestation. Neurology 1999; 52: 750-756.

27. Hishida, R. and Nau, H. VPA-induced neural tube defects in mice. I. Altered metabolism of sulfur amino acids and glutathione. Teratog Carcinog Mutagen 1998; 18: 49-61.

28. Lampen A, Siehler S, Ellerbeck U, Gottlicher M, Nau H. New molecular bioassays for the estimation of the teratogenic potency of valproic acid derivatives in vitro: Activation of the peroxisomal proliferators-activated receptor (PPARdelta). Toxicol Appl Pharmacol 1999; 160: 238-49.

29. Finnell RH, Wlodarczyk BC, Craig JC, piedrahita JA, Bennett GD. Strain-dependent alterations in the expression of folate pathway genes following teratogenic exposure to valproic acid in a mouse model. Am J Med Genet 1997; 70: 303-11.

30. Okada A, Aoki Y, Kushima K, Kurihara H, bailer M, Fujiwara M. Polycomb homologs are induced in teratogenecity of valproic acid in mice. Birth Defects Res A Clin Mol Teratol 2004; 70: 870-9.

31. Tamai H, Wakamiya E, Mino M, Iwakoshi M. Alphatocopherol and fatty acid levels in red blood cells in patients treated with antiepileptic drugs. $J$ Nutr Sci Vitaminol 1988; 34: 627-31.

32. Dansky LV, Rosenblatt DS, Andermann E. Mechanism of teratogenesis: folic acid and antiepileptic therapy. Neurology 1992; 42: 32-42.

33. Bailey LB, Gregory JF 3rd. Folate metabolism and requirements. J Nutr 1999; 129: 779-82.

34. James SJ, Pogribna M, Pogribny IP et al. Abnormal folate metabolism and mutation in the methylenetetrahydrofolate reductase gene may be maternal risk factors for Down syndrome. Am J Clin Nutr 1999; 70: 495-501.

35. Bailey CJ, Pool RW, Poskitt EM, Harris F. Valproic acid and fetal abnormality. Br Med J 1983; 286: 190.

36. Emmanouil-Nikoloussi EN, Foroglou NG, KerameosForoglou CH, Thliveris JA. Effect of valproic acid on fetal and maternal organs in the mouse: a morphological study. Morphologie 2004; 88: 41-5

37. Cotariu D and Zaidman JL. Developmental toxicity of valproic acid. Life Sci 1991; 48: 1341-50.

38. Keil U, Scherping I, Hauptmann S, Schuessel K, Eckert A, Muller WE. Piracetam improves mitochondrial dysfunction following oxidative stress. Bri J pharmacol 2006; 147: 199-208.

39. Gabryel B, Adamek M, Pudelko A, Malecki A, Trzeciak HI. Piracetam and vinpocetine exert cytoprotective activity and prevent apoptosis of astrocytes in vitro in hypoxia and reoxygenation. Neurotoxicology 2002; 23: 19-31.

40. Moriau M, Crasborn L, Lavenne- Pardonge E, Von Frenckell R, Col-Debeys C. Platelet antiaggregant and rheological properties of piracetam. A pharmacodynamic study in normal subjects. Arzneimittelforschung 1993; 43: 110-18.

41. Nalbandian RM, Henry RL, Burek CL et al. Diminished adherence of sickle erythrocytes to cultured vascular endothelium by piracetam. Am J Hematol 1983; 15: 147-51. 